\title{
Scleroderma en coup de sabre treated with polymethylmethacrylate - Case report ${ }^{*}$
}

\author{
Joanna Pimenta de Araujo Franco ${ }^{1}$ \\ Ricardo Barbosa Lima ${ }^{1}$ \\ Carlos José Martins ${ }^{1}$
}

\author{
Márcio Soares Serra ${ }^{1}$ \\ Antônio Macedo D'Acri ${ }^{1}$
}

\begin{abstract}
The scleroderma en coup de sabre is a variant of localized scleroderma that occurs preferentially in children. The disease progresses with a proliferative and inflammatory phase and later atrophy and residual deformity, which are treated with surgical techniques such as injectable fillers, transplanted or autologous fat grafting and resection of the lesion. Among the most widely used fillers is hyaluronic acid. However, there are limitations that motivate the search for alternatives, such as polymethylmethacrylate, a permanent filler that is biocompatible, non-toxic, non-mutagenic and immunologically inert. In order to illustrate its application, a case of scleroderma en coup de sabre in a 17-year-old patient, who was treated with polymethylmethacrylate with excellent aesthetic results, is reported.
\end{abstract}

Keywords: Atrophy; Cicatrix; Cosmetic techniques; Polymethyl methacrylate; Scleroderma, localized

\section{INTRODUCTION}

The scleroderma en coup de sabre is a variant of linear or localized scleroderma that occurs preferentially in children. It may involve all of the hemiface, extending from the scalp to the the nose, lips and tongue. ${ }^{1,2}$ Its etiology is unknown, but probably it is of autoimmune nature. ${ }^{1,3,4}$ Besides the skin lesions, neurologic and ophthalmologic abnormalities may occur. There may be cicatricial alopecia (scarring hair loss), hyperchromic and depressed residual lesions. ${ }^{2}$

The treatment for localized scleroderma consists of inhibition of the proliferative and inflammatory phase of the disease, which is done by means of oral medication like corticosteroids, cyclophosphamide, methotrexate, cyclosporine, pentoxifylline and penicillamine, among others, as well as topical medication, such as corticosteroids, tacrolimus, pimecrolimus and colchicine. ${ }^{4}$ In the phase of residual atrophy and deformity, the treatment of choice is done with surgical techniques such as injectable fillers, transplanted or autologous fat grafting and resection of the lesion. ${ }^{1,2}$

Among the fillers, the most widely used is the hyaluronic acid, a hygroscopic, absorbable gel. ${ }^{5}$ However, limitations like durability and cost of the filler are factors that lead to the search for other alternatives. We report a case of scleroderma en coup de sabre treated with polymethylmethacrylate (PMMA), with the objective of illustrating a little-used option.

\section{CASE REPORT}

Male patient, 14-year-old, with scleroderma en coup de sabre for 6 years. There was no neurologic or ophthalmologic abnormality. The examination revealed an atrophic and depressed lesion that extended from the forehead to the scalp, with alopecia. At first he was treated with colchicine ointment,

Received on 22.07.2014

Approved by the Advisory Board and accepted for publication on 04.11.2014

Work carried out at the Hospital Universitário Gafrée e Guinle, Universidade Federal do Estado do Rio de Janeiro (HUGG-UNIRIO) - Rio de Janeiro (RJ), Brazil.

Financial Support: None.

Conflict of Interest: None.

1 Hospital Universitário Gaffrée e Guinle - Universidade Federal do Estado do Rio de Janeiro (HUGG-UNIRIO) - Rio de Janeiro (RJ), Brazil. 
clobetasol cream and intralesional triamcinolone. Three years after the skin lesion became stable the PMMA filling was done in 3 sessions, with a 3-month interval between sessions. The procedure was started after the custodial person was informed about possible complications and signed a consent form.

PMMA 10\% was used in the forehead with retroinjections in thin cylinders, crossed in $\mathrm{X}$ with the purpose of raising the skin, maintaining flexibility without adding too much volume (Figure 1). In the scalp, PMMA $30 \%$ was used with retroinjections in thicker cylinders, forming a network to produce more volume. After the treatment, we observed raising of the depressed portion and partial hair regrowth in the alopecia area of the scalp (Figure 2). When inquired about the degree of satisfaction regarding the result of the treatment in a zero to ten scale, the patient answered nine.

\section{DISCUSSION}

The scleroderma en coup de sabre is a type of linear scleroderma that may produce disfiguring scars. There are some surgical therapeutic options for the treatment of residual atrophy. ${ }^{1}$ Among them are injectable fillers (hyaluronic acid, PMMA, calcium hydroxylapatite), transplanted or autologous fat grafting and resection of the lesion. ${ }^{1}$

It is important to emphasize that injectable fillers should only be used when the skin lesion is stable, that is, without growth or alterations in consistency or skin color. However, the patient should be warned that the treatment does not prevent from a possible relapse to the proliferative phase, since disease activity lasts around 3 to 5 years and may extend up to 25 years, with an uncertain progression time. ${ }^{2,3}$

We chose PMMA because it is a permanent filler, biocompatible, not toxic, non-mutagenic and immunologically inert. PMMA does not require
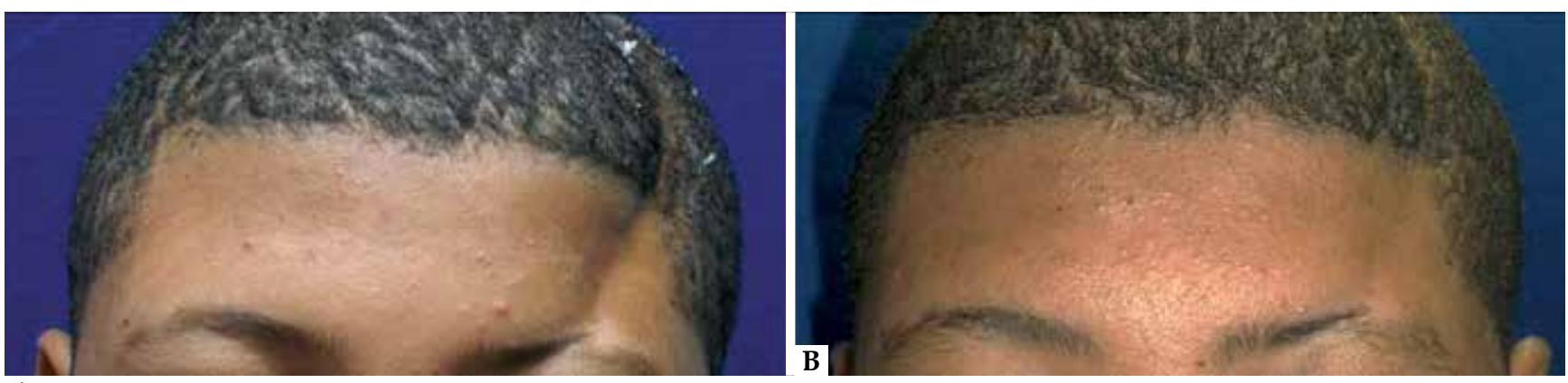

A

Figure 1:Patient before (A) and after (B) the third session of PMMA at 10\% in the frontal region
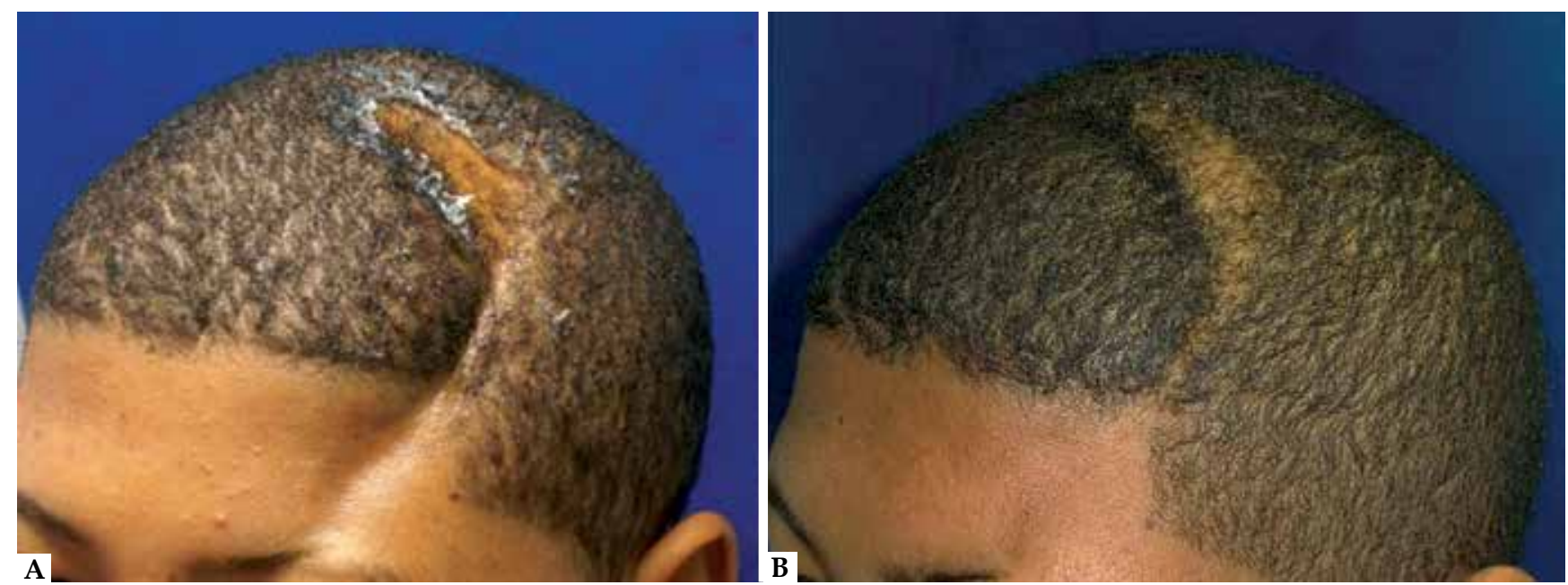

Figure 2: Patient before (A) and after (B) the third session of PMMA at $30 \%$ in the scalp 
a previous cutaneous test as its microspheres are $100 \%$ polymerized. Therefore, allergies are rare. ${ }^{6} \mathrm{We}$ use it in $10 \%$ and $30 \%$ concentrations. ${ }^{2}$ Besides these advantages, one of the factors that made us choose the product was its ready availability at our service, since the patient did not have the means to purchase the medication.

After a PMMA application, there is a reaction of foreign body type that induces the onset of giant cells that wrap each particle of the product, leading to new collagen and blood vessels formation. That means that the defect is corrected by the volume of the product added and the incorporation of cells and collagen fibers that appear at the site. ${ }^{7}$

\section{REFERENCES}

1. Choksi AN, Orringer JS. Linear morphea-induced atrophy treated with hyaluronic acid filler injections. Dermatol Surg. 2011;37:880-3.

2. Duarte AA. Colagenoses e a dermatologia. 2 ed. Rio de Janeiro: Di Livros; 2012.

3. Burns T, Breathnach S, Cox N, Griffiths, editors. Rook's textbook of dermatology. 8th ed. New York: Blackwell Science; 2010.

4. Zancanaro PCQ, Isaac AR, Garcia LT, Costa IMC. Localized scleroderma in children: clinical, diagnostic and therapeutic aspects. An Bras Dermatol. 2009;84:161-72.

5. Beasley KL, Weiss MA, Weiss RA. Hyaluronic acid fillers: a comprehensive review. Facial Plast Surg. 2009;25:86-94.

6. Carvalho Costa IM, Salaro CP, Costa MC. Polymethylmethacrylate facial implant: a successful personal experience in Brazil for more than 9 years. Dermatol Surg. 2009;35:1221-7.

7. Sandoval MHL, Ayres EL. Preenchedores: Guia Prático de Técnicas e Produtos. São Paulo: AC Farmacêutica; 2013.

8. Serra MS, Oyafuso LK, Trope BM, Munhoz Leite OH, Ramos-e-Silva M. An index for staging facial lipoatrophy and evaluation of the efficacy of the treatment with polymethylmethacrylate in HIV/AIDS patients: a pilot study. J Eur Acad Dermatol Venereol. 2013;27:990-6.
According to the instructions accompanying the product, PMMA is recommended for facial and body volume correction and also to correct lipodistrophy caused by use of antiretrovirals in patients with HIV. ${ }^{8}$ Its use has also been reported for treatment of acne scars and facial lipoatrophy induced by cutaneous lupus panniculitis. ${ }^{8}$

Based on this information and the result obtained for the patient described, PMMA filling is a good therapeutic option for esthetic improvement of residual scarring following scleroderma and an alternative to avoid more invasive surgical procedures.

\author{
MAILING ADDRESS: \\ Joanna Pimenta de Araujo Franco \\ Rua Mariz e Barros 775 \\ Tijuca \\ 20270-004 - Rio de Janeiro - RJ \\ Brazil \\ E-mail: jopimentafn@yahoo.com.br
}

How to cite this article: Franco JPA, Serra MS, Lima RB, D'acri AM, Martins CJ. Scleroderma en coup de sabre treated with polymethylmethacrylate - Case report. An Bras Dermatol. 2016;91(2):209-11. 